\title{
Análise do princípio constitucional da dignidade humana face a dimensão da afetividade e o direito fraternal ${ }^{1}$
}

\section{An analysis of the constitutional principle of human dignity in view of the dimension of affectiveness and fraternal law}

\author{
Lafayette Pozzoli (*) \\ lara Rodrigues de Toledo ${ }^{(* *)}$
}

Recebido: $11 / 2016$

Aprovado: 02/2017

\begin{abstract}
Resumo: $O$ artigo apresenta um estudo sobre o princípio da dignidade humana e a forma de sua efetividade. O trabalho da doutrina, após a Constituição de 1988, resultou em várias teses sobre este tema. Da análise identificou-se a aplicação deste princípio uma vez analisado cada ato do universo jurídico com uma carga de valores próprios de uma sociedade ou de uma parcela desta sociedade, baseando-as nas condutas morais e éticas de cada sociedade que são possíveis de serem encontradas na mera compreensão das práticas sociais. Junte-se a isto o princípio da afetividade, instituto do Direito de Família, que aqui é tomado como ferramenta importante na efetividade do direito, conjuntamente com o princípio da fraternidade. A afetividade, no sentido da responsabilidade de uma pessoa com a outra, potenciando seus sentimentos, e a fraternidade tornam-se categorias importantes no processo de efetivação dos direitos. O direito que busca a paz entre os seres humanos e que lhes gera o instinto de vida fraterna num clima de afetividade, ou seja, de responsabilidade de um cidadão para com o outro. O começo da concreta efetivação de uma norma jurídica se dá com a sua plena correlação com os valores existentes na sociedade, num processo de conscientização. Os princípios da afetividade e da fraternidade, lastreados no princípio da dignidade da pessoa humana como um farol que ilumina todo o ordenamento jurídico. O direito voltado para a proteção e segurança da dignidade da pessoa humana, que muito ajuda na construção de uma cidadania responsável na busca de uma sociedade solidária, justa e fraterna, sem exclusão de qualquer segmento social.
\end{abstract}

Palavras-chave: Dignidade humana; Fraternidade; Afetividade; Humanismo jurídico; Filosofia do direito.

\begin{abstract}
The article presents a study on the principle of human dignity and the form of its effectiveness. The work of doctrine, after the 1988 Constitution, resulted in several theses on this topic. From the analysis the application of this principle was identified once considered every act of the juridical universe with a load of values proper of a society or a part of this society, basing them on moral and ethical conduct of each society that are able to be found in the mere understanding of social practices. Join to this the principle of affection, institute of the Family Law, which here is taken as an important tool in the effectiveness of law, in conjunction with the principle of fraternity. The affection in the sense of responsibility of one person to another, enhancing their feelings, and fraternity become important categories in the process of realization of the rights. The right that seek peace among human beings and that generate them the instinct of fraternal life in a climate of affection, ie of responsibility of a citizen to each other. The beginning of the concrete realization of a rule of law is with its full correlation with the values in the society, in an
\end{abstract}

\footnotetext{
* Pós-Doutorado pela Universidade "La Sapienza", Roma, Itália. Mestrado e Doutorado em Filosofia do Direito pela PUC/SP. Coordenador do Mestrado em Direito no UNIVEM. Advogado. Professor no UNIVEM. Foi Professor e Chefe de Gabinete na PUC-SP. Membro do Conselho Editorial da Revista EM TEMPO (UNIVEM) e da Revista de Direito Brasileira - RDBras, do CONPEDI. Líder do Grupo de Pesquisa GEP - Grupo de Estudos, Pesquisas, Integração e Práticas Interativas, cadastrado no Diretório de Grupos de Pesquisas do CNPq. E-mail: lafayette@lafayette.pro.br.

** Pós-Doutorado pela Faculdade de Direito da Universidade de Lisboa, Portugal. Mestre e Doutora pela Pontifícia Universidade Católica de São Paulo - PUC-SP. Advogada. Procuradora do Estado de São Paulo aposentada. Foi Docente do Programa de Pós-Graduação em Direito - Mestrado em Direito - do UNIVEM / Marilia-SP. E-mail: iarardetoledo@uol.com.br

Problemata: R. Intern. Fil. v. 8. n. 1 (2017), p. 178-190 e-ISSN 2236-8612

doi:http://dx.doi.org/10.7443/problemata.v8i1.27851
} 
awareness process. The principles of affection and fraternity, backed in the principle of human dignity as a beacon that illuminates the entire legal system. The law towards the protection and safety of human dignity, which greatly helps in building responsible citizenship in search of a caring society, just and fraternal, without exclusion of any social segment.

Keywords: Human dignity; Fraternity; Affection; Legal humanism; Philosophy of law.

\title{
Introdução
}

\begin{abstract}
Volto a São Tomás, que diz o seguinte: Os princípios são universais e as suas aplicações variam na medida em que as circunstâncias historicamente se apresentam. No entanto, há certos princípios que são fundamentais, por exemplo, na ordem prática, o respeito à dignidade da pessoa humana, com o apoio da justiça, que é um valor universal, mas nas suas aplicações, há todo um fator histórico que leva constatar seu processo em cada realidade.
\end{abstract}

André Franco Montoro

O artigo aprofunda um estudo sobre o princípio da dignidade humana em que vemos não ser o mesmo dogmatizado conceitualmente, podendo ser exemplificado por maio de alguns tipos legais, porém, deve-se permitir sua análise com toda subjetividade que lhe é próprio.

A doutrina tem trabalhado, especialmente após a Constituição de 1988, várias teses sobre este tema. Diante do aspecto subjetivo do que vem a ser dignidade humana, pode-se concluir que o direito à vida, como um direito mais protegido pelo ser humano, está em um mesmo nível de valor da dignidade humana. Isto porque não é possível dar o direito a vida sem preservar um mínimo de dignidade ao ser humano que é detentor deste direito.

Uma grande dificuldade encontrada quando o tema é a dignidade humana, trata-se da sua efetividade. É possível a aplicação deste princípio uma vez que podemos analisar cada ato do universo jurídico com uma carga de valores próprios de uma sociedade ou de uma parcela desta sociedade, baseando-as nas condutas morais e éticas de cada sociedade que são possíveis de serem encontradas na mera compreensão das práticas sociais.

O princípio da afetividade, do Direito de Família, aqui é tomado como ferramenta importante na efetividade do direito, conjuntamente com o princípio da fraternidade.

É seguindo este raciocínio que a afetividade, no sentido da responsabilidade de uma pessoa com a outra, potenciando seus sentimentos, e a fraternidade tornam-se categorias importantes no processo de efetivação dos direitos. Algo relativamente novo no estudo doutrinário e timidamente exercido no âmbito judicial, no entanto, os valores presentes na sociedade brasileira já comportam seguramente tal exercício.

Por fim, quando é aceita a dignidade humana com uma carga 
valorativa intensa e realmente praticada e aceita no universo jurídico, estamos diante de um direito que não prima pelo texto que foi escrito, seja ele atual ou retrogrado, mas, um direito que busca a paz entre os seres humanos e que Ihes gera o instinto de vida fraterna num clima de afetividade, ou seja, de responsabilidade de um cidadão para com o outro.

\section{A dignidade humana e o direito a vida}

O princípio da Dignidade Humana está disposto no Título I da Constituição Federal, no artigo $1^{\circ}$, in verbis:

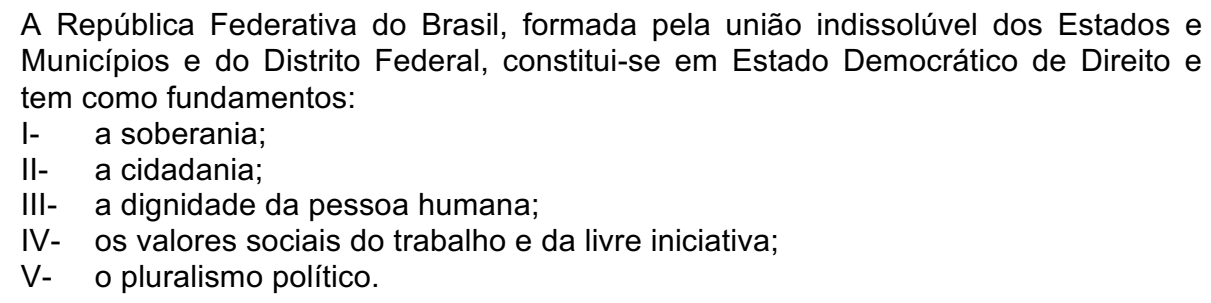

A aplicação deste princípio não está determinada, não encontramos no texto Constitucional norma regulamentadora do referido princípio, entendendose assim, que o artigo $3^{\circ}$, da Carta Magna, demonstra exemplos de quais seriam os direitos de garantia da dignidade humana. Dispõe o Art. $3^{\circ}$ da CF88:

\footnotetext{
Constituem objetivos fundamentais da República Federativa do Brasil:

I- construir uma sociedade livre, justa e solidária;

II- garantir o desenvolvimento nacional;

III- erradicar a pobreza e a marginalização e reduzir as desigualdades sociais e regionais;

IV- promover o bem de todos, sem preconceitos de origem, raça, sexo, cor, idade, e quaisquer outras formas de discriminação.
}

Nessa seara, não há de olvidar-se que estamos diante de um rol meramente paradigmático que o legislador apresentou para nortear o que deve entender a hermenêutica jurídica no tocante a dignidade humana.

Assim, torna-se inevitável a aplicação do princípio da proporcionalidade na tentativa de valorar os direitos entendidos como de dignidade do ser humano e o direito mais preservado pela racionalidade humana que é o direito a vida. Nesse embate, entendemos que tais direitos não devem ser distintamente valorados, sendo que estão no mesmo nível de igualdade por sua importância fundamental, sendo que, com uma análise humanística, podemos concluir pela não existência de uma vida humana se esta não é 
provida de um mínimo de dignidade. Neste sentido, bem afirma Edson Fábio Garutti Moreira:

O ser humano é "pessoa" por não ser objeto nem animal, mas ser dotado de racionalidade e vontade, e é "pessoa humana" porque também é dotado de uma individualidade, isto é, forma um todo completo em si, uma vez que possui valores humanos e um espírito digno de respeito e liberdade (2001, p. 23).

Seguindo este raciocínio, é justo sustentar que tal tipo de dignidade é inerente ao comportamento humano, mas que a dignidade prescrita na Constituição Federal de 1988 reporta-se a um atributo próprio do ser humano, como um valor de todo o ser racional e em virtude disso é que uma pessoa não pode ser privada de seu direito fundamental - a vida. Isto remete sistematicamente à necessidade da discussão jurídica da dignidade humana, como sendo a garantidora da vida humana.

\section{Dignidade humana e sentido da vida}

O ser humano moderno elegeu como direito de principal proteção e cuidado, o direito a vida. Com toda razão, de que valeriam códigos, leis e normas de conduta na esfera jurídica, se não existir uma vida a ser tutelada, um sujeito. Assim, uma vez que o direito a vida é indisponível, surge a questão no sentido de que, do que valeria uma vida por si só? Ou ainda, existe uma vida se ela não tem um valor ou sentido de ser?

É com tal raciocínio que conseguimos chegar ao ponto em que é indispensável para se falar em proteção a vida, sem fazer dela uma carga de valores particulares ou somente sociais.

Portanto, no intuito de agregar à vida esse valor, que é inerente ao ser humano, surge a necessidade de salvaguardar a dignidade humana, para que haja sentido na proteção desse bem tão precioso que é a vida humana. $O$ Professor Fernando Ferreira dos Santos ensina que:

A proclamação do valor distinto da pessoa humana terá como consequência lógica a afirmação dos direitos específicos de cada homem, o reconhecimento de que, na vida social, ele, homem, não se confunde com a vida do Estado[...] (1999, p. 20).

Tendo como referência a dignidade do ser humano é fácil identificar seu critério subjetivo, já que cada ser humano possui sua própria dignidade, não perante o Estado, mas perante sua sociedade, o que assim, passa a ter, a dignidade humana, valor em "pé de igualdade" à vida do homem, vez que, um não tem sentido sem o outro. Ainda com Fernando Ferreira dos Santos: 
Consequentemente, cada homem é fim em si mesmo. E se o texto constitucional diz que a dignidade da pessoa humana é fundamento da República Federativa do Brasil, importa concluir que o Estado existe em função de todas as pessoas e não estas em função do Estado (1999, p. 92).

Podemos exemplificar de várias formas o que seria uma vida digna que, mesmo já estudado ser inerente a cada ser humano em si, pode ser facilmente protegida, no seu mínimo, pelo detentor do Direito que é o Estado.

Enfim, o ser humano digno é aquele que tem valores agregados a sua vida, valores esses instituídos pela sociedade em que vive bem ou por si próprio, que o Estado pode e consegue muitas vezes reconhecer, a exemplo do disposto no artigo $5^{\circ}$ da Constituição Federal. Assim ensina Willis Santiago Guerra Filho:

Ademais, o "respeito a dignidade humana, à qual se reporta a idéia democrática, requer uma concepção diferenciada do que seja 'segurança', 'igualdade', 'justiça', 'liberdade', etc., onde o ser humano jamais pode ser tratado como 'objeto' e 'meio' de realização de qualquer desses valores, mas sim os sujeitos a que eles se referem e à promoção de quem essa realização tem por finalidade.

Não há que se falar assim, que cabe apenas à particularidade de cada ser humano sua defesa à dignidade, mas ao detentor do direito, o Estado, cabe a responsabilidade de garantir ao cidadão sua dignidade humana como forma de fazer valer sua "autoridade democrática".

\section{Dignidade humana, afetividade e fraternidade}

A dignidade humana, como vimos anteriormente, pode ser entendida de diversas formas, considerando a cultura de cada povo, da mesma forma, há que se falar em um fio condutor que perpassa o todo da história humana caracterizando o princípio da dignidade humana com a vida de cada ser humano.

Não podemos falar em dignidade sem proporcionar a igualdade entre os seres humanos. Igualdade material e não igualdade no sentido formal da palavra, conforme afirma Lafayette Pozzoli, em seu livro:

Por outro lado, o conceito material de igualdade apresenta uma conceituação no campo social e observa regra semelhante ao conceito formal, pais a igualdade está em tratar desigualmente os desiguais. A presença do valor "justiça" é uma constante; assim, ao afrontar o princípio da igualdade tratando igualmente os desiguais, estaria gerando uma visível situação de injustiça.[...]

A paz, assim como a justiça, tem em vista o bem de cada pessoa e de todos, numa 
exigência de ordem e verdade. Estando a paz sob a mira da ameaça, atinge simultaneamente a justiça (2001, p. 106/108).

Assim, a afetividade e o Direito Fraterno, parceiros nos relacionamentos e sentimentos humanos poderão contribuir para encontrar 0 ponto de equilíbrio da efetiva igualdade entre as pessoas, eliminando o direito à igualdade baseado em um poder soberano, a quem todos estão subordinados, porque o direito à igualdade deixa de ser efetivo em decorrência das desigualdades que ele mesmo impõe, a começar pela subordinação dos povos a um poder soberano, um poder desigual.

Pensando neste sentido, o princípio dignidade humana, como fundamento do Estado e garantidor da vida, é possível dizer que estamos diante de uma humanização do direito, ou ainda, de um direito mais digno.

Tal entendimento sobre a preocupação com a dignidade da pessoa humana, nada mais é do que falar na afetividade presente e característica do ser humano e no direito fraterno.

Toda a primeira parte do Preâmbulo da Constituição Federal refere-se à afetividade que o cidadão brasileiro deve ter um com o outro, notadamente quanto ao princípio ali contido do bem-estar. A fraternidade, por mais que esteja em nossas culturas sua relação com a religião, aqui, fica claramente apresentada como o grande objetivo da organização jurídica. A ordem jurídica, fundada no princípio da igualdade e da paz, voltada para a dignidade da pessoa humana, é o ordenamento da fraternidade. O ser humano não deve ser visto apenas como um ser que existe, mas deve ser visto essencialmente como um ser que vive em sociedade.

A fraternidade não deve ser vista apenas como uma ordem suprema ou mística, mas, principalmente, como uma necessidade para uma melhor convivência em sociedade. É assim que leciona Carlos José Teixeira de Toledo:

\footnotetext{
$\mathrm{Na}$ medida em que vivemos em um mundo globalizado, não só econômica, mas culturalmente, o valor da tolerância e do respeito à alteridade se faz cada vez mais necessário, devendo o Estado, na qualidade de árbitro dos valores sociais, desfazerse de qualquer liame religioso que impeça o correto exercício de sua função em prol do verdadeiro interesse público (2004, p. 240).
}

Então, ao tratarmos da fraternidade no universo jurídico como uma essência da ordem jurídica, precisamos nos atentar para as medidas em âmbito jurídico que devem assegurar ao ser humano digno um direito fraterno. É possível identificar que sob o manto do princípio da dignidade humana começa-se a reconhecer o valor da afetividade como um instrumento importante na efetividade do direito. 
O exemplo de maior amplitude e historicamente marcado na vida humana, foi sem sombra de dúvidas, a elaboração da Declaração Universal dos Direitos Humanos, da ONU, maior documento jurídico produzido pela humanidade no século $X X$, cujo conteúdo demonstra claramente um único objetivo universal que é o da busca da paz, o que faz com que o ordenamento jurídico tenha intrínseca ligação com o que afirmamos ser fraternidade. Sobre este assunto, afirma Lafayette Pozzoli:

\begin{abstract}
A referida declaração, objeto de um estudo mais específico no item seguinte, consigna no seu texto o reconhecimento da dignidade da pessoa humana inerente a todos os membros da família humana e de seus direitos iguais e inalienáveis como constitutivos do fundamento da liberdade, da justiça e da paz. Foram elementos importantes que tornaram os direitos da pessoa humana protegidos, para que a pessoa não se veja levada ao supremo recurso da revolta contra a tirania e a opressão (2001, p. 110).
\end{abstract}

A fraternidade é uma nova possibilidade de integração entre os povos e nações, fundamentada no cosmopolitismo, em que as necessidades vitais serão suprimidas pela amizade, pelo pacto jurado conjuntamente.

Com a Declaração Universal dos Direitos Humanos, de 1948, o compromisso dos ideários foi praticamente universalizado. Conforme dispõe no seu art. $1^{\circ}$, "todos os homens nascem livres e iguais em dignidade e direitos. São dotados de razão e consciência e devem agir uns aos outros com espírito de fraternidade" e no art. 29, item 1, outra importante disposição: "toda pessoa tem deveres para com a comunidade, em que o livre e pleno desenvolvimento de sua personalidade é possível".

A idéia de "jurar em conjunto" é também um requisito básico e que dá fundamento para que um novo humanismo brilhe. Este novo conceito tem vínculos com um futuro mais fraterno, em que os acordos são estabelecidos entre os iguais. Não é mais o direito comandado por um "Pai-soberano".

Um novo conceito ou novo/velho pressuposto, muitas vezes esquecido ou contaminado é a amizade, que no mundo moderno nada mais que se faz do que acelerar seu processo ambivalente, representada pelo paradoxo inclusão/exclusão.

Certamente que estas reflexões sobre as questões suscitadas poderão contribuir para a construção de um novo paradigma para o sistema do direito em especial, e, também, para o sistema da política.

Vale aqui reproduzir o Preâmbulo da Constituição Federal de 1988, em que o Constituinte teve inspirações fundamentadas nos valores que permeiam a sociedade brasileira, notadamente a parte que faz referência a uma "sociedade fraterna". In verbis: 
Nós, representantes do povo brasileiro, reunidos em Assembleia Nacional Constituinte para instituir um Estado Democrático, destinado a assegurar o exercício dos direitos sociais e individuais, a liberdade, a segurança, o bem-estar, o desenvolvimento, a igualdade e a justiça como valores supremos de uma sociedade fraterna, pluralista e sem preconceitos, fundada na harmonia social e comprometida, na ordem interna e internacional, com a solução pacífica das controvérsias, promulgamos, sob a proteção de Deus, a seguinte Constituição da República Federativa do Brasil.

\section{Cidadania e dignidade humana: caminho da paz}

Nos últimos tempos é possível constatar que muitos relacionamentos entre pessoas (e também entre alguns Estados) têm sofrido pequenos abalos.2 Talvez isto vem ocorrendo devido ao fato de que nos aproximemos mais intensamente do processo de globalização, intensificando a dimensão da comunicação.

Para analisar a questão, tomemos, de maneira analógica, o seguinte exemplo: existe uma perfeita ordem no universo e que - tudo indica - parece contrastar com uma assim chamada desordem que costuma reinar entre as pessoas e povos, como se as suas mútuas relações não pudessem ser reguladas senão pela força! Aliás, uma concepção errônea, mas freqüente, que leva muitos a julgar que as relações de convivência entre as pessoas e a sua respectiva comunidade política possam reger-se pelas mesmas leis das forças e dos elementos "irracionais" do universo. Mas a verdade é que, sendo leis de gênero diferente, deve-se buscar apenas onde as inscreveu o Criador de todas as coisas, a saber, na natureza humana.

São, de fato, essas leis que indicam claramente como regular na convivência humana as relações das pessoas entre si, as dos cidadãos com as respectivas autoridades públicas. As relações entre os diversos Estados, bem como as das pessoas e comunidades políticas com a comunidade mundial, cuja criação é hoje urgentemente postulada pelo bem comum universal que tem na fraternidade um instrumento de grande valia.

Em uma convivência humana bem constituída e eficiente é fundamental o princípio de que cada ser humano é pessoa, isto é, natureza dotada de inteligência e vontade livre. Por essa razão, possui em si mesmo direitos e deveres, que emanam direta e simultaneamente de sua própria natureza. São direitos e deveres universais, invioláveis e inalienáveis.

O Estado de direito garante a inviolabilidade da dignidade da pessoa humana através da ordem jurídica. Assim, falar em paz é falar da Declaração Universal dos Direitos Humanos3, da ONU, que representa um conjunto de aspirações proclamadas como ideal comum de todos os povos que buscam a 
paz. Nela foi resumido o conjunto de valores presentes nos quatro cantos do planeta, tornando-a um documento histórico e da maior importância, produzido em meados do século $X X$.

A referida declaração consigna no seu texto o reconhecimento da dignidade da pessoa humana inerente a todos os membros da família humana e de seus direitos iguais e inalienáveis como constitutivos do fundamento da liberdade, da justiça e da paz. Foram elementos importantes que tornaram os direitos da pessoa humana protegidos, para que a pessoa não se veja levada ao supremo recurso da revolta contra a tirania e a opressão.

Objetivando mais facilmente alcançar a paz entre as nações, para que os Estados-membros da ONU pudessem convalidar em seus respectivos ordenamentos jurídicos da Declaração, foram aprovados em 1966 os Pactos: Pacto Internacional dos Direitos Econômicos, Sociais e Culturais e Pacto Internacional dos Direitos Civis e Políticos4. Com isto os Estados-membros assumiram a condição de coadjuvantes partícipes da paz.

Os respectivos pactos, ou melhor, os Direitos Humanos, foram concebidos como proposta de um sistema de vida integral que abarcasse todos os âmbitos, o cultural, o econômico, o político e o social, tanto a nível individual como coletivo, e aplicável a todos, sem qualquer discriminação. Este um desejo de sobrevivência cada vez mais profundo à medida que cresce a ameaça. Não se contentam em proclamar a sede da vida dos seres humanos, mas tentam permitir concretamente a sobrevivência. Enfim, o exercício da cidadania pode intensificar o processo de discussão de um projeto de desenvolvimento que aponta para o bem comum, coisa salutar desde que seja observado o respeito à dignidade da pessoa humana a todos, sem distinção.

Resta uma análise da efetividade da fraternidade com sua correlação com a dignidade humana. Para tanto, devemos investigar o direito com a sua função promocional da pessoa humana.

\section{Afetividade e fraternidade: a efetividade do direito como função promocional da pessoa humana}

O que caracteriza o direito positivo, no mundo contemporâneo, é uma contínua mudança. Por isso mesmo torna-se difícil identificar o jurídico só pelo conteúdo. Daí a necessidade de conhecer, identificar e qualificar as normas como jurídicas pela sua forma. A este respeito Hans Kelsen deu uma contribuição teórica, de admirável rigor, ao elaborar, no âmbito da sua teoria, o princípio da dinâmica do direito, graças ao qual uma norma é válida não porque tem um certo conteúdo, mas sim porque foi formalmente criada de acordo com as normas previstas no ordenamento, e dentre elas as do Preâmbulo da 
Constituição Federal de 1988, como visto no item anterior.

Com isto não é difícil identificar no direito um instrumento promocional da pessoa humana, não sendo tão somente um direito punitivo, mas um direito fraternal. É neste sentido que afirma Franco Montoro:

O fim do Direito é ordenar a vida da sociedade, orientando a conduta de seus membros e a atividade de suas instituições. Para esse objetivo, ele estabelece normas e procura garantir a eficácia das mesmas, atribuindo conseqüências positivas a seu cumprimento e negativas ou punitivas à sua violação. Ver no Direito apenas o aplicador de sanções punitivas é diminuí-lo. (1999, p. 252.

É a nova forma de ver/analisar/aplicar o direito. Aliás, o uso de estímulos positivos, de maneira preponderante o fraternal, em relação aos aspectos negativos passa a ser uma característica das diversas ciências, não se circunscrevendo tão somente ao direito, afinal os humanistas, o humanismo, estão presentes nos diversos setores da sociedade.

É com as indicações acima ponderadas que teoria geral do direito formal para poder compreender melhor o tipo de normas que tratam dos direitos humanos e, notadamente do direito fraternal, embebido do princípio da afetividade na sua relação característica de responsabilidade mútua, considerando tal direito com a sua efetiva aplicação, ou seja, o exercício da cidadania.

\section{Considerações finais}

Por derradeiro, é neste sentido que a afetividade e a fraternidade, presente atualmente no âmbito do direito, deixou a muito de ser uma preocupação somente para os teólogos, filósofos, psicólogos etc. A afetividade e o direito fraterno hoje são direitos do ser humano como pessoa digna, que deve o Estado garantir tal segurança, sendo ambos os princípios auxiliam na efetividade do direito.

Cabe notadamente aos juristas posicionar e lutar por este direito, mas também, uma tarefa-dever de todos os cidadãos. A afetividade como valor jurídico em nada difere do direito fraterno. Ambos podemos considera-los como racionais, lógicos e totalmente possíveis como demonstrado, e por isso merece a atenção de todos os cidadãos e, notadamente, a classe dos agentes do direito que são os maiores responsáveis pelas mais diversas doutrinas existentes no mundo jurídico.

A defesa pela afirmação do princípio da afetividade e do direito fraterno é a garantia de que teremos uma ordem jurídica voltada para o ser humano na sua dignidade e com isso, a conquista de um direito cada vez mais justo, atingindo a máxima eficácia no controle social pleno para o qual foi criado. 
O começo da concreta efetivação de uma norma jurídica se dá com a sua plena correlação com os valores existentes na sociedade, num processo de conscientização. Assim, como analisado, no contexto há que ser observados os princípios da afetividade e da fraternidade, lastreados no princípio da dignidade da pessoa humana como um farol que ilumina todo o ordenamento jurídico. Em síntese, vale ressaltar, um direito voltado para a proteção e segurança da dignidade da pessoa humana, que muito ajuda na construção de uma cidadania responsável na busca de uma sociedade solidária, justa e fraterna, sem exclusão de qualquer segmento social.

\section{Referências}

AQUINO, Santo Tomas de. Suma de teología. Trad. José Martorell Capó. $2^{a}$ ed. Madrid: Biblioteca de Autores Cristianos, 1997.

ARENDT, Hannah. Entre o passado e o futuro. São Paulo: Perspectiva, 1979.

ARISTÓTELES. Política. Brasília: ed. UNB, 1988.

BOBBIO, Norberto. A era dos direitos. Trad. Carlos Nelson Coutinho. Rio de Janeiro: Elsevier, 1992.

BRITTO, Carlos Ayres. O Humanismo como categoria constitucional. Belo Horizonte: Fórum, 2010.

CÂMARA, Maria Helena F. da. Bem comum. In: Revista Forense, Vol. 327, julho - agosto - setembro, Rio de Janeiro: Forense, 1994. pp. 297 - 301.

CASO, Giovanni. Direito e Fraternidade. São Paulo: LTr - Cidade Nova, 2008.

FERACINE, Luiz. Direito, Moral, Ética e Política. $1^{\text {a }}$ Ed. Campo Grande: Solivros, 2000.

FRANCISCO, Papa. A Igreja da Misericórdia: minha visão para a Igreja. São Paulo: Paralela, 2014.

. O nome de Deus é Misericórdia. São Paulo, Planeta, 2016.

GIACOIA Jr, Oswaldo; RAMIRO, Caio Henrique Lopes; RICCI, Luiz Antonio Lopes. Responsabilidade e Futuro: bioética, biopolítica, biopoder e os desafios para a reflexão e ação. São Paulo, Editora LibrerArs, 2015.

GUERRA FILHO, Willis Santiago. Ensaios de teoria constitucional. Fortaleza: Ed. Universidade Federal do Ceará, 1989.

IHERING, Rudolf Von. A Luta pelo direito. Tradução de João Vasconcelos. Rio de Janeiro: Forense, 1990.

LAFER. Celso. A reconstrução dos direitos humanos. São Paulo: Cia. das Letras, 1988.

LORENZO, Wambert Gomes DI. Teoria do Estado de Solidariedade: da 
dignidade da pessoa humana aos seus corolários. Rio de Janeiro: Elsevier, 2010.

MONASSA, Clarissa Chagas Sanches; POZZOLI, Lafayette. Fraternidade e Sustentabilidade no Direito. Curitiba - PR: Instituto Memória, Centro de Estudo da Contemporaneidade, 2015.

MONTORO, André Franco. Estudos de filosofia do direito. São Paulo: RT, 1999.

MARITAIN, Jacques. Humanismo Integral. São Paulo: Companhia Editora Nacional, 1945.

. Os direitos do homem e a lei natural. 3. ed. Rio de Janeiro: Livraria José Olympio Editora, 1967.

MOREIRA, Edson Fábio Garutti. Humanismo de Maritain e a Burocracia. Coleção Instituto Jacques Maritain do Brasil. São Paulo: Edições Loyola, 2001.

MORENTE, Manuel Garcia. Fundamentos de filosofia. São Paulo: Mestre Jou, 1980.

NALINI, José Renato. Uma nova ética para o juiz. São Paulo: RT, 1994.

PLATÃo. A República. $5^{a}$ ed., Lisboa: Fundação Calouste Gulbenkian, 1987.

POZZOLI, Lafayette. Maritain e o Direito. Coleção Instituto Jacques Maritain do Brasil. São Paulo: Edições Loyola, 2001.

Direito como função promocional da pessoa humana: inclusão da pessoa com deficiência - fraternidade (artigo) - Livro: Gramática dos Direitos Fundamentais - a Constituição Federal de 1988 - 20 anos depois. Coletânea organizada por Thereza Christina Nahas, Norma Sueli Padilha e Edinilson Donizete Machado, Campus, 2009.

. Reflexos das normas internacionais e da Constituição Federal de 1988 nas políticas públicas de inclusão social no Brasil a pessoa com deficiência (artigo). Livro: Constituição, Minorias e Inclusão Social. Coletânea organizada por Antonio Celso Baeta Minhoto, Rideel, 2009.

ALVIM, Márcia Cristina de Souza (Orgs.). Ensaios sobre filosofia do direito - Dignidade da Pessoa Humana, Democracia e Justiça. Coletânea. São Paulo: Educ/Fapesp, 2011.

SANTOS, Fernando Ferreira dos. Princípio Constitucional da Dignidade da Pessoa Humana. Publicação do Instituto Brasileiro de Direito Constitucional. São Paulo: Celso Bastos Editor, 1999.

SOUZA, Carlos Aurélio Mota de. Direitos humanos, urgente! São Paulo: Oliveira Mendes, 1998.

A fraternidade como categoria jurídica no direito ambiental. In: SANTOS, Ivanaldo; POZZOLI, Lafayette. Direito humanos e fundamentais e doutrina social. 1. Ed. Birigui, SP: Boreal Editora, 2012.

TOLEDO, Carlos José Teixeira de. Nós Somos um Estado Laico? Um Estudo 
Histórico-constitucional, v.3, p. 221-241. São Paulo: Uninove, 2004.

TOLEDO, lara Rodrigues de; PEREIRA, Sarah Caroline de Deus; MENDES, Daiane Cristina da Silva. (Orgs.) Estudos acerca do princípio da afetividade no Direitos das Famílias. São Paulo, Letras Jurídicas, 2014.

\footnotetext{
${ }^{1} \mathrm{O}$ tema deste artigo é objeto de pesquisas com discussões no Grupo de Pesquisa: GEP Grupo de Estudos, Pesquisas, Integração e Práticas Interativas, desde 2009, trabalhado em Grupo de Trabalho do Conpedi, cujas discussões no GT proporcionou um grande enriquecimento ao tema. A partir de 2015 iniciamos uma integração com o Grupo de Pesquisa GPEA - A ética do afeto: os direitos da personalidade no Direito de Família, acrescendo no artigo os novos estudos realizados.

2 Em 2009 a ONU proclamou o Ano Internacional da Reconciliação. Conforme Resolução da Assembléia Geral das Nações Unidas (61/17). Em 2015 (nov/15 a out/16) o Papa Francisco proclamou o Jubileu da Misericórdia.

${ }^{3} \mathrm{O}$ maior documento jurídico produzido pela humanidade no Século $X X$.

${ }^{4}$ O Brasil já convalidou em seu ordenamento jurídico os respectivos pactos em 1992.
} 